\title{
Debatable Issues of English Writing Apprehensions: A Qualitative Study of Taiwanese English Majors' Perspectives
}

\author{
Grace Hui Chin Lin ${ }^{1}$, Patricia J. Larke ${ }^{2}$, Douglas S. Jarvie ${ }^{3} \&$ Paul Shih Chieh Chien ${ }^{4}$ \\ ${ }^{1} \mathrm{PhD}$, Curriculum and Instruction, Texas A\&M University College Station, Master of Science in Teaching \\ English as a Sceond Language, Rossier School of Education, University of Southern California \\ ${ }^{2}$ Full-Professor, Department of Teaching, Learning \& Culture, Texas A\&M University, USA \\ ${ }^{3}$ Lecturer, The English Language Center, Tunghai University, Taichung, Taiwan \\ ${ }^{4}$ Associate Professor, Center for General Education, National Taipei University of Business, Taipei, Taiwan \\ Corresponding: Grace Hui Chin Lin, 154, Chang Lu Road, Changhwa, 50083, Taiwan. Tel: 886-933-503-321. \\ E-mail: lingrace_us@hotmail.com, lingrace_us@yahoo.com
}

Received: November 20, 2017 Accepted: December 2, 2017 Online Published: December 4, 2017

doi: 10.5539/elt.v11n1p33 URL: http://doi.org/10.5539/elt.v11n1p33

\begin{abstract}
Anxiety (e.g., Dallos, 1976, 2006; Krashen, 2003, 2016) sometimes might be unavoidable in the learning process, because the cognitive and intellectual systems are usually connected with emotional factors. This empirical study was conducted in an English majors' advanced-level writing course to explore relevant explanations about why Taiwanese university students experienced "anxiety" (Tomlinson, 1981, 2016). Seventeen participants of junior grade at a southern Taiwan university had cooperated with their teacher to examine their anxiety occurring during writing in English. The findings discovered five key issues explaining their apprehension including mentioned (1) time restriction, (2) teacher evaluation, (3) peer competition, (4) uninteresting writing topics. The fifth factor repeated by most of the student is displayed by this study. The study implies the anxiety should be a negative impact upon language learning.
\end{abstract}

Keywords: academic writing, affective factors, qualitative study, raising awareness, writing anxiety

\section{Introduction}

Based on potential anxiety issues affecting learners' writing proficiency, scholars associated with psychological factors have discussed how to minimize emotional blocks upon language learning (e.g., Wilce, 2009). Most studies agree with that the learning apprehensions cause students feel frustrating and becoming weaker in learning process. (Krashen, 2016, Tomlinson, 1981, 2016) Students tend to feel be demotivated in writing can hold negative attitude toward their writing tasks, producing papers of low quality, have negative impressions of their own writing and are more likely to avoid situations where writing is required (Ho, 2016; Sanders-Reio, et al, 2014). Hence, promoting learners' affirmative attitudes for learning has become a fundamental key to an effective and successful writing course.

This study raises awareness of anxiety factors in Taiwanese English majors. Certain key factors were revealed, aiming to discover more and different fretfulness factors in order to ascertain new results. In prior decades, there has been lots of multi-perspectives and multi-directional results. Some scholars in contrast reported anxiety has positive influence upon learning (Coutu, 2002), or vice versa (Meijer \& Oostdam, 2011). Additionally, some scholars have studied anxiety by analyzing the human brain and neural systems (Lewis, 2005).

Recently, some studies (e.g., Niles, 2014; Wynne, 2014) designed diverse tasks to help students increase students' perceived stress and prevent them from completing their writing projects on time. The varieties influence teaching and learning can be addressing specific emotions of enjoyment, interest, curiosity, pride, anxiety, confusion, shame, and boredom emotions in academic content domains (mathematics, science, and reading/writing), contextual factors (classroom, family, and culture), and teacher emotions. (Bohn-Gettler \& Rapp, 2014) Similarly, this study hopes to present a dissimilar direction, raising awareness of updated anxiety causing factors and inspecting related issues. Different factors like time, peers, (Chang, 2004) from Taiwan non-native speakers' views have been overlooked in preceding studies. A new factor related to English writing 
structure and differentiated styles from Chinese writings has been discussed.

\section{Literature review}

\subsection{Multi-perspective Study}

Writing can be turned to hard, due to symptoms caused by anxiety. (Colleen, 2017) When examining prior studies, several directions were considered to be imperative. First, it is important to understand the relationship between anxiety and learning as positive or negative. It's also important to take into account what signs of anxiety can be seen, and what reflective pedagogical solutions are available. Secondly, teachers should be aware of both already discovered and invisible potential factors causing anxiety, as mentioned in current literature. Thirdly, it is vital to have applicable measuring scales that can be utilized to evaluate learner's anxiety levels.

\subsection{Interactive Cognizant and Neural Systems}

Anxiety is unavoidable in language learning situations. The cognitive and intellect systems are both closely related to the emotional system. These two systems are interactive in the brain, so affective factors can influence learning results. Phelps (2005) explains both cognitive attentiveness to the emotional impact of events, and cognizant submission through affection strategies can control amygdale functions and emotional expressions. Emotions can influence cognition and perception by harmonizing and qualifying attention and perception, through the amygdale in the limbic system. According to Phelps (2005), human being's two neural systems of emotion and cognition coexist in both independent and interdependent ways. So, a thorough realization requires attention and inspection of the complicated and mixed interactions involving both systematical organizations, including cognizant and affective ones.

Likewise, Lewis (2005) believes that "dynamic system analysis of the neurobiology of emotion then demonstrates, in precise and concrete terms, that cognition and emotion were never two distinct systems at all." (p. 194) Lewis connects cognition and emotion. "Although it remains useful to differentiate cognition and emotion for many research agendas, a neuro-scientific analysis finds them to be different aspects of a unitary phenomenon in which interpretation and relevance emerge together." (Lewis, 2005, p. 194)

Correspondingly, Dai and Sternberg (2004) also hold a similar attitude and contend intellectual functioning and development never occur as solely cognitive events, but can also involve an individual's motivation and emotions, or the whole person's capacity of vis-a-vis adaptive challenges. "Going beyond cognitivism does not imply that motivational and emotional issues are more important than or as important as cognitive process and mechanisms." (p. 29)

In fact, academic scholars might not be able to properly understand the cognitive processes involved. However, reducing intellectual functioning to merely cognitive matters is simply no longer justifiable both on theoretical grounds and in light of empirical evidence. Numerous scholars also argue that anxiety has a mostly negative effect on learning (e.g., Guo \& Wang, 2014; Jee, 2015; Tomlinson, 1981, 2016; Yan \& Wang, 2012). They do not believe it automatically translates into the stimulation of encouraging behaviors. "Though some language researchers assert that a positive mode of anxiety exists, most language research shows a negative relationship between anxiety and performance." (Arnold, p. 60) The negative anxiety is sometimes called "debilitating anxiety." It harms learners' performances indirectly, by worry and self-doubt, and directly, by reducing participation and creating unconcealed avoidance in language.

\subsection{Oxford's Signs of Anxiety and Solutions}

Oxford (1999) has contended without an instrument like the Foreign Language Classroom Anxiety Scale (FLCAS), signs of language anxiety can be still recognized by the following signs of general avoidance, physical actions, psychical symptoms and some other psychological signs. This indicates the students can perceived anxiety by their own bodies and learning conditions.

First of all, general avoidance to learn and write by students can be displayed by several phenomena. They can be forgetting the answer, carelessness, cutting class, coming late, arriving unprepared, low levels of verbal production, lack of volunteering in class, and a seeming inability to answer even the simplest questions. Secondly, physical actions can be presented by squirming, fidgeting, playing with hair or clothing, nervously touching objects, stuttering or stammering, displaying jittery behavior, and being unable to reproduce the sounds or intonation of the target language even after repeated practice. The above biased behaviors also can be observed by the teachers or peers. Thirdly, learners' physical symptoms of a headache, tight muscles, unexplained pain or tension in any part of the body might appear in class. Other signs of anxiety might manifest, depending on the culture; over-studying, perfectionism, social avoidance, conversational withdrawal, lack of eye contact, hostility, monosyllabic or noncommittal responses, image protection or masking behaviors (exaggerated 
smiling, laughing, nodding, joking), failing to interrupt when it would be natural to do so, excessive competitiveness, excessive self-effacement and self-criticism. For example, "I am so stupid."

\subsection{Sources and Effects of Anxiety}

Horwitz (1986) looks into how anxiety is generated. The self-consciousness and anxiety could be caused by the mismatch between mature thought available to express in articles, but immature foreign and second language proficiencies for writing down in the actual paper. That is, adult learners cannot unreservedly express their in-depth thoughts or philosophies like writing in first language. Due to linguistic limitations in comparison to native speakers, their psychological stress is unavoidably formed.

Whether anxiety is an advantage or disadvantage remains to be a controversial issue, debating by the fieldworkers. Onwuegbuzie et al. (1999) have declared in a wide-ranging tone, "Foreign language anxiety is a complex phenomenon that has been found to be a predictor of foreign language achievement." (p. 217). Anxiety might play the dual roles of a stimulant and an obstacle. Some scholars even believe it to be positive impact upon language learning. Young (1992) has conducted a study inspecting language acquisition from the points of view of Rardin, Omaggio Hadley, Terrell and Krashen. He indicates that Rardin argues that a positive aspect of anxiety operates all the time, but we only notice this effect if a negative imbalance occurs. Omaggio Hardley similarly suggests a certain amount of tension might be positively constructive for language learning, so she refused to term this tension 'anxiety.' Correspondingly, Terrell prefers to call such tension 'attention,' rather than 'anxiety.' However, Krashen (2003) strongly challenges previous scholars and says there is no accommodating aspect to apprehension in language acquisition.

\subsection{Measuring Scales}

Negative emotion can originate from more than a few typical reasons that might still be somewhat new or unfamiliar to scholars, so it needs to be discussed continuously. Recently, Dornyei (2009) gives an explanation of negative anxiety: "Everybody knows that classrooms are venues for a great deal of emotional turmoil, yet affect has been an almost completely neglected topic in educational psychology." (p. 219)

As Dorneyi (2009) states, “...we know very little about the role of pleasant emotions, such as enjoyment, happiness, hope, surprise, anticipation, or pride, and unpleasant emotions (other than anxiety), such as anger, fear, sadness, hopeless, disgust, shame, guilt, or boredom." (p. 221) These types of sentiments can be interactively connected to learners' multi-psychological statuses and sometimes even cause anxiety. To what level some negative drives can develop into learning anxiety can be measured by several frequently applied scales, such as Daly and Miller's (1975) Writing Apprehension Test (WAT), English Writing Block Questionnaire (EWBQ) created by Rose (1984) and the English Classroom Anxiety Scale adapted by Gardner (1985).

Secondly, researches have centered on probable factors and have provided some effective solutions that might reduce students' fear. Lee (2001) suggests finding the appropriate reasons for writing apprehension during the revision process and topic preference, which could help students learn writing. Additionally, Rollinson (2005) offers a solution to release students' writing anxiety through peer feedback in a second language writing class.

Furthermore, criteria could be designed to assess reasons and degrees of anxiety, based on each possible rationalization, providing solutions such as peer correction to reduce students' emotional blocks. Several researchers (e.g., Worde Von, 2003) focus on the subjects' physical manifestations, such as blushing and perspiring. Bishop et al (2001) reveal that somatic anxiety was the solitary significant predictor of pain tolerance among participants with tension headache. From physiological perspectives, the impact of anxiety on L2 writing is an urgent matter attracting serious attentions from English teachers.

\subsection{Diverse Factors Causing Writing Anxiety}

In addition to the previous discussions how anxiety and learning can be connected and the variable factors of writing anxiety, some other types of research relating to this issue can be found. For example, Levine (2003) reports students from monolingual backgrounds tend to feel more anxious than students from bi- or multilingual backgrounds. Daud et al. (2005) discuss how subjects suffer anxiety because of the lack of writing skills, and the interesting fact that better students experienced less anxiety.

\section{Significance of Study}

Many previous studies have been based on the theoretical foundations of affective factors discussing the solutions using diverse pedagogies of teaching and learning academic writing. However, less qualitative studies arguing major factor of anxiety from English majors' detailed reasons for the anxious psychological status can be found. 


\section{Methodology}

This study involved seventeen junior students in a national university who were just starting to write research papers, and were willing to cooperate to inspect anxiety. The advanced writing course for English majors lasted for 18 weeks in a semester. Thorough descriptions of student perceptions were collected by way of a twenty-minute, face-to-face interview after taking the advanced writing III course for 17 weeks. This writing course was the highest level among a series of required writing courses for nine credits.

\subsection{Research Questions}

1). What are the nervousness-provoking factors of writing activities inside and outside of English writing classrooms?

2). What are the solutions to release Taiwanese university students' stress and negative emotions?

3). How can students' writing anxiety be perceived and measured?

\subsection{Research Setting}

In a Department of Foreign Languages and Literature, 17 English majors were taking their three-hour writing course in a fall semester. The title of the highest-level writing is Advanced Writing III, which is the last required English writing course before graduation. The participants were from different areas of Taiwan, including Taipei, Taichung, Tainan, Kaohsiung, Pingtung and Hualien. Furthermore, the group included two overseas students from Hong Kong and Macao.

The students were instructed in basic writing frameworks on how to write five-paragraph essays based on topics from the Test of English as a Foreign Language (TOEFL) and analytical essays from The International English Language Testing System (IELTS). Most importantly, they were taught 13 types of English format writing, including Comparison and Contrast, Cause and Effect, Narration, etc. Moreover, university students were also guided to write English poetry and commercial product advertisements. Instructions provided by the lecturer mostly consisted of strategies for writing standard research papers.

\subsection{Data Collection}

The students' statements were collected by a digital (MP3) recorder. After two months of the writing course, students were invited to talk about their possible anxiety factors in a face-to-face interview of twenty minutes and submit their feedback written on survey sheets. They were allowed to feely talk about anything in the teacher's office, and were encouraged to talk about factors they perceived as causing nervousness.

\subsection{Data Analysis}

Based on several open-ended questions, students provided detailed descriptions of their own observations and experiences during learning. Constant comparison analysis was utilized to analyze perceptions of negative emotions appearing in learning writing. The analysis method was used by the researchers to consistently find the subjects' parallel statements under several dissimilar themes and categories existing in research subjects' descriptions. Then, the researchers systemized and conceptualized them into several chief conceptions, as the findings outline (Glaser \& Strauss, 1999).

\subsection{Assumptions}

1). It is hypothesized that most of the subjects' statements of the possible factors of writing anxiety will be related to previous studies focusing on this issue.

2). It is assumed this research might reveal newer causes.

\subsection{Limitations}

The results cannot represent the entire population of English learners of Taiwan, because only

17 English majors in a top-ten university were surveyed.

\subsection{Triangulations}

To reconfirm the analyses and concluding themes, emails and telephone calls were applied by the researchers one month after the data collecting. Revealed themes were confirmed and more details were provided by participants for clarifying their perceptions and attitudes.

\section{Results}

Time limitation, teachers' evaluation, peer competition, uninteresting subjects, and uniformed writing formats, were the main factors. The sequence of each factors from English majors' views is the updated outcomes. 


\subsection{Time Restriction Factor}

This issue was mentioned primarily by three students. They felt nervous when thinking of the "time limitation", during testing or class practice activities. They have psychological and physical reactions to their apprehension. Outcomes of the anxiety can be low grades and even course failure, impeding the schedule of assignment submission and even graduation form school. After analyzing the narrative data, the outcome can be interpreted by the three participants. They explained their causes and effects of writing anxieties that they had perceived in this course.

Student 1: Writing apprehension frequently occurs when the in-class writing time is inadequate, especially during examinations. To be clearer, I cannot perform at one hundred percent of my actual ability in time-constrained special circumstances within 20 minutes or half hour. Two years ago, I was taking my college entrance test; a strong feeling of anxiety overwhelmed me. I was hit with the realization that only several minutes left for me to finish composing an article. My body froze while sitting on the chair in the quiet testing room. My pen was grabbed too tightly, my test paper was damp due to my sweaty palms and I felt stupid because my mind was blank.

Student 2: In time-limited writing like quizzes and take home assignments, I would be exceedingly panicky and pay too much unnecessary attention to the time rather than the already-achieved proportion of the progressed schedule. As a consequence, I became obsessed by my own meaningless anxiety about there being a lack of time. This led to writing anxiety and a negative circle that I cannot finish the writing on time. My experiences taught me that fretfulness plays an important role in my writing performance and my train of thought in writing with a foreign language can easily be broken.

Student 3: I feel the strongest element of anxiety for me is time restriction. This can be clearly seen when I am requested to complete assignments within time limits. Based on my own experiences of submitting homework, if students cannot finish their assignments on time, they may not get a good grade. Also, the required number of words causes anxiety. Sometimes the expected number may be too high, so I worry about not being able to fulfill my teacher's expected word numbers a short interval of time by high-level vocabularies and grammatical structures.

\subsection{Teacher Evaluation Factor}

The four participants mentioned their anxiety might be generated by the teacher's evaluations and negative comments on their work. Participants put too much emphasis on the teachers' grading, so apprehensions are caused by needs of dignity and support by the teacher, disappointment due to low grades and English majors' low-level writing skills in comparison to native speakers. Also, one participant thought literature writing such as poetry writing could not be fairly graded, due to the subjective nature of literature.

Student 1: There were several reasons, but the major one was that I really care about the comments from my teachers. I feared they disliked my work, or that I was being ignored by no comments, or frustrated by their words. I was afraid of failure, so I became too cautious in grammar, structure and word choice. Writing for a reader who has been really critical or demanding in the past also gave me a lot of pressure while I was writing. I still remember having a really picky English teacher in my high school years. He often criticized my English writing, no matter how well I did. Every time I got my paper back, he always gave me a poor evaluation. I was dissatisfied so my writing motivations were eliminated.

Student 2: It is common for students to care about the teacher's evaluation of their writing and I am no exception. Whenever I get a composition with my teacher's remarks on it, I expect to get his or her support and a good evaluation. I find the more I get good evaluations from my teacher, the better I do on my writing. A teachers' positive evaluation gives you confidence in writing.

Student 3: Every time I am writing, I always think of how the professors would correct me. I am afraid of hearing professors telling me I made the same mistakes as before. My teachers might think she has an English major student who cannot write like a native speaker in elementary school. If they say so, then I am not able to make progress.

Student 4: The pressure definitely stems from teachers' evaluation. Writing scores reflect whether my writing is bad or good. Also, high expectations sometimes made me surrender by doing nothing, so an authoritarian teacher would hinder me in writing well. Professors might point out my weaknesses. Therefore, when I am creating, I will sometimes worry about the criticism. Creative writing like poems is subjective. Some people might personally relate to what I write but some people might not. As a result, although I am afraid of being criticized, I realized it's impossible for everyone to enjoy my composition and free verse after experiencing so many 
comments from teachers.

\subsection{Peer Competition Factor}

Five participants emphasized peer comments and competitive attitudes were the most important reason why they felt anxious in the writing course. Especially, in a top university, peer competition naturally can become a significant factor.

Student 1: No wonder personal pressure causes suffering. There is no denying writing well will give me a good reputation among my peers. When something involves self-esteem or dignity, it will be very serious. Face issues are important. I do not like to give speeches or presentations about my writing.

Student 2: There are so many classmates that can really do a terrific job because they have lived in an English-speaking country for a long time. Such students higher the standards of our department and give me a lot of pressure, especially, I need to discuss about my writing with them.

Student 3: I am afraid my writing will make others feel this kind of writing should not come from a student who studies foreign language and literature. I hope my writing reaches a quality that everybody from our department is supposed to reach.

Student 4: I am applying scholarship and my writings should be outstanding to achieve this. I really care about my peers' views toward my writings. Therefore, I feel the safest type of writing to keep from anxiety is keeping a diary. A diary is not originally meant to be seen by others. There is almost no anxiety for me when I am writing a diary.

Student 5: Writing an essay as homework is stressful since my score will be compared with my peers. I am afraid to listen to the model articles that the teacher recite for a peer.

\subsection{Writing Subject Factor}

Topics can affect students' emotions. Five students regarded this as the greatest factor in influencing emotions. If they have never heard the topics introduced by the teachers or read in the reference books, they start to feel frustrating without too much confidence. Subject knowledge is related to the anxiety.

Student 1: My writing apprehension is usually caused by the fact that I am not interested in the subjects assigned. When I really know very little about the topics assigned to me.

Student 2: I feel nervous to make up something unreal. I am a person who requires real experience in daily life to write well.

Student 3: When using imagination for writing, my ears tingle. I feel dishonest.

Student 4: I was a very gifted writer, when I was just a little child. I was able to creatively and freely write down my thinking without being taught and assigned subjects. However, when I grew up, I was often assigned uninteresting writing topics at school.

Student 5: My imagination and creativity for writing was limited by exam situations.

\subsection{English Writing Format Factor}

The influence of writing format or structure on anxiety is a newfound factor in this research after repeating the mentioned factors to the students before training, with no sufficient previous research data available in Taiwan. Among 17 participants, eight students expressed their difficulties in cultural differentiated styles and two students strongly agree with the same repeated factor by more detailed illustrations. The eight English majors expressed their difficulties from the diversity of English writing styles, and the apparent differences between English and Chinese formats.

Student 1: These formats are not easy to master from views of Taiwanese students, due to cultural shock caused by differentiated educational background from elementary schools and junior/senior high schools. Student 2: If students are finding English concepts and format of writing to be demanding, it severely adds to their anxiety level. The formats can be regulated English formats not familiar by Chinese students

Student 3: I am not familiar with the formats: 1. Process writing, 2. comparison and contract writing, 3. argumentation and critical writing 4 . chronological writing or 5. cause and effect writing.

Student 4: Finally yet importantly, dealing with diverse new forms of English writing really makes me anxious. It is the first time that I have been informed that the styles are so different, including Comparison and Contrast, Cause and Effect, Analytical Writings.

Student 5: When I read the syllabus addressing more than ten formats, my face was hot and red. Due to being 
unfamiliar with the new forms, I often feel helpless while I am writing in advanced-level at university.

Student 6: To solve structure problems, I must get the work started early and practice new formats of writing every day for being familiar with them, although this is stressful.

Student 7: The Chinese writing format is more familiar and easier, which is "qĭ chéng zhuăn hé". It can be applied to all topics of Chinese writing. However, English has diverse formats regulated in advanced-level writing at university and graduate schools, including Narrative, Augmentative, Cause and Effect, and Descriptive essays. They are too different from one type of Chinese writing and we have never learned it in Chinese writing.

Student 8: Although we had learned five paragraph English writing previously before junior grade, we had never learn these complex styles in English previously. Whenever I think of the series of widely divergent structures that I have to learn in this semester of only 18 weeks, I feel headache and my palms sweat. While I asked my peers about the new styles, they are not familiar with it and we do not really share our updated thinking toward the styles. This also caused face problems and peer competition problems. It would take me a long time to be a good English writer.

\subsection{Analytical and Evaluative Comments}

Through above analysis of the qualitative data collected from face-to-face interviews, it is possible to understand how the participants perceived somatic anxiety and cognitive anxiety. Most of the themes from students' descriptions were mentioned by previous research, including grading (Chang, 2004), other students (Chang, 2004), time constraints (Chang, 2004), and difficulties caused by uninteresting subjects (Lee, 2001). One significantly argued factor found is the uniformed writing formats.

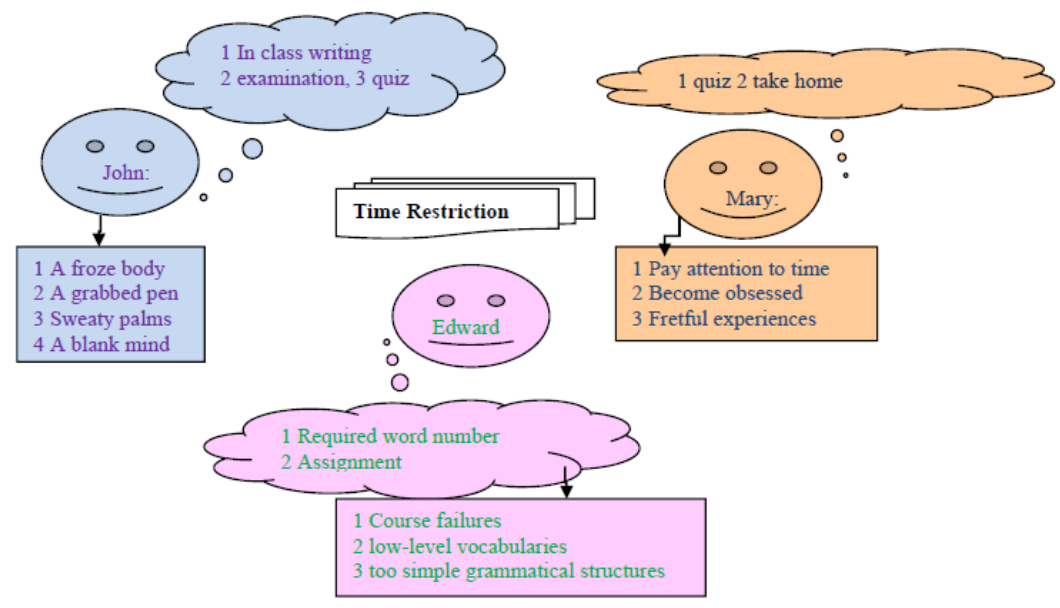

Graph 1. Time issue by students' interpretations

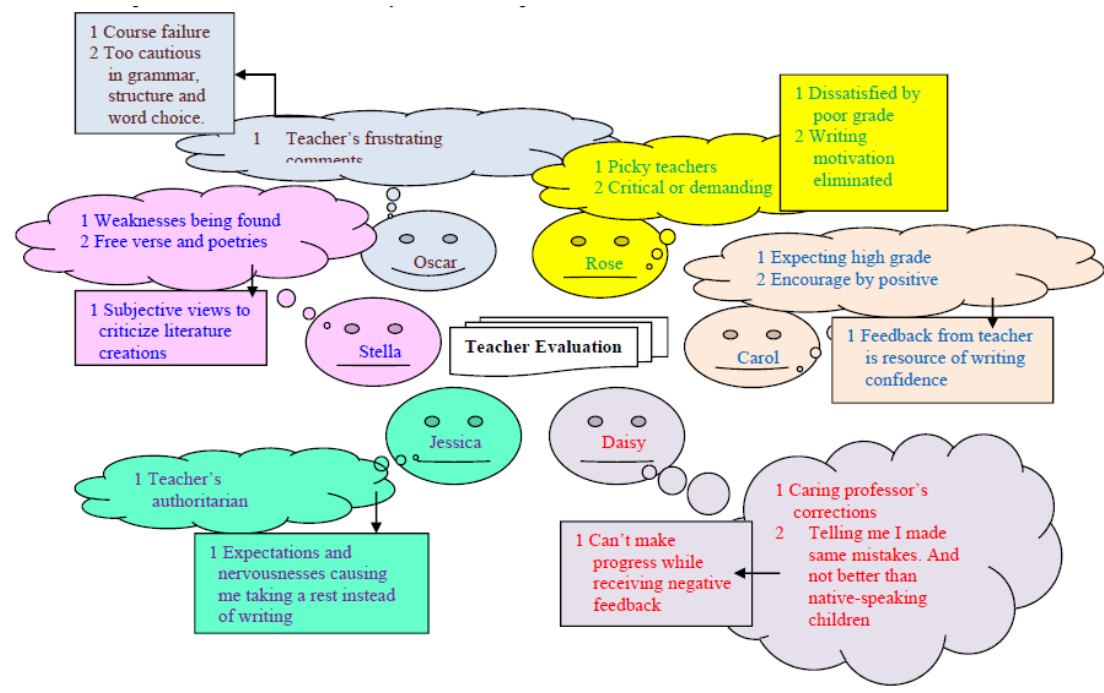

Graph 2. Teacher evaluation issue by students' interpretations 


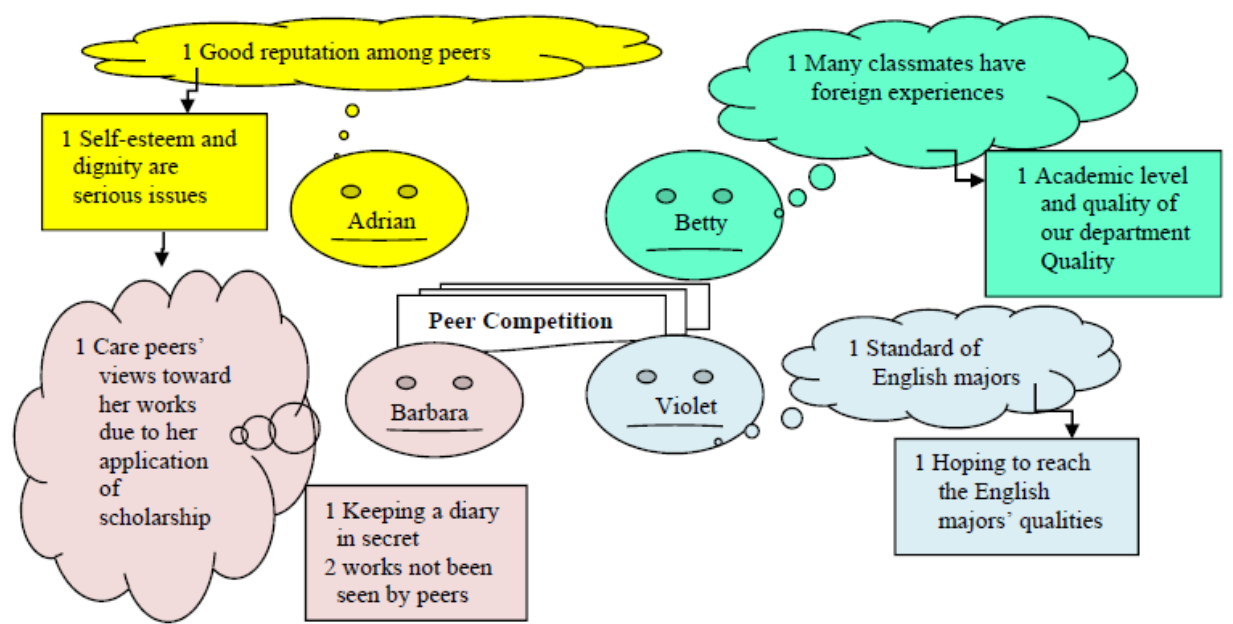

Graph 3. Peer completion issue by students' interpretations

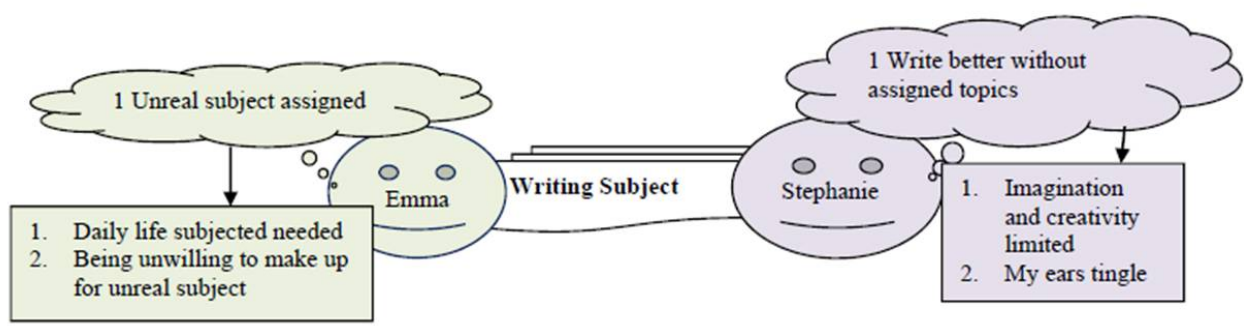

Graph 4. Subject Issue by students' interpretations

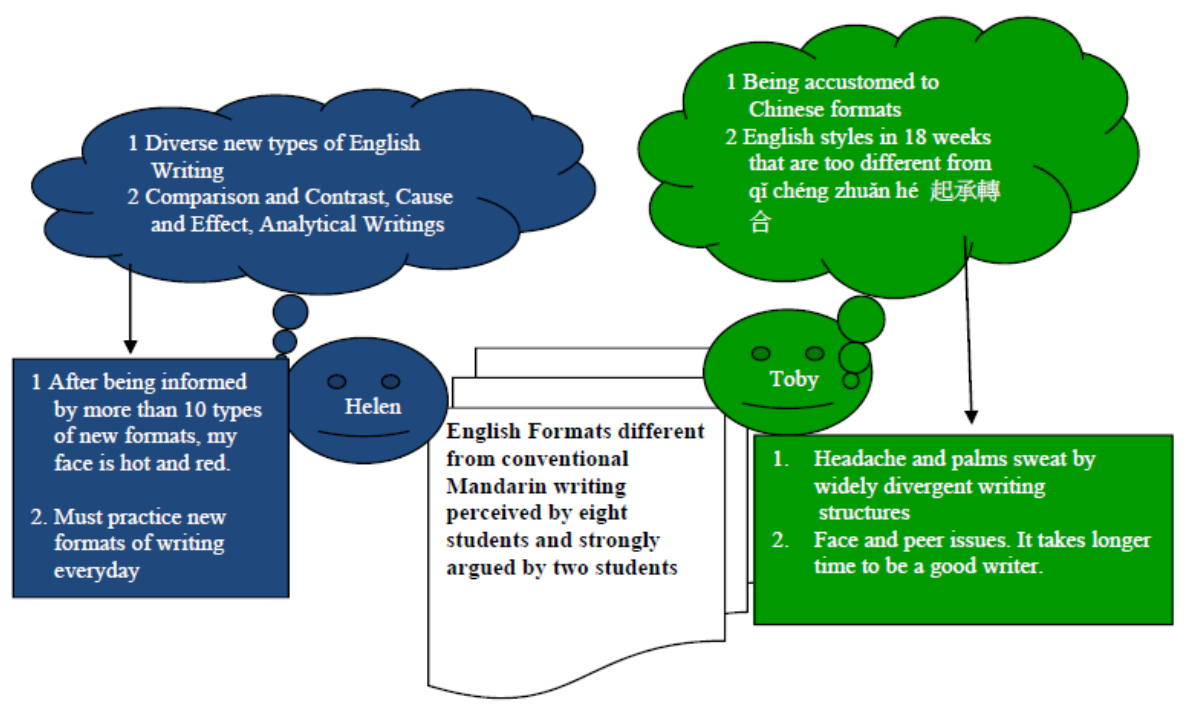

Graph 5. English Format Issue repeated by eight students' interpretations 


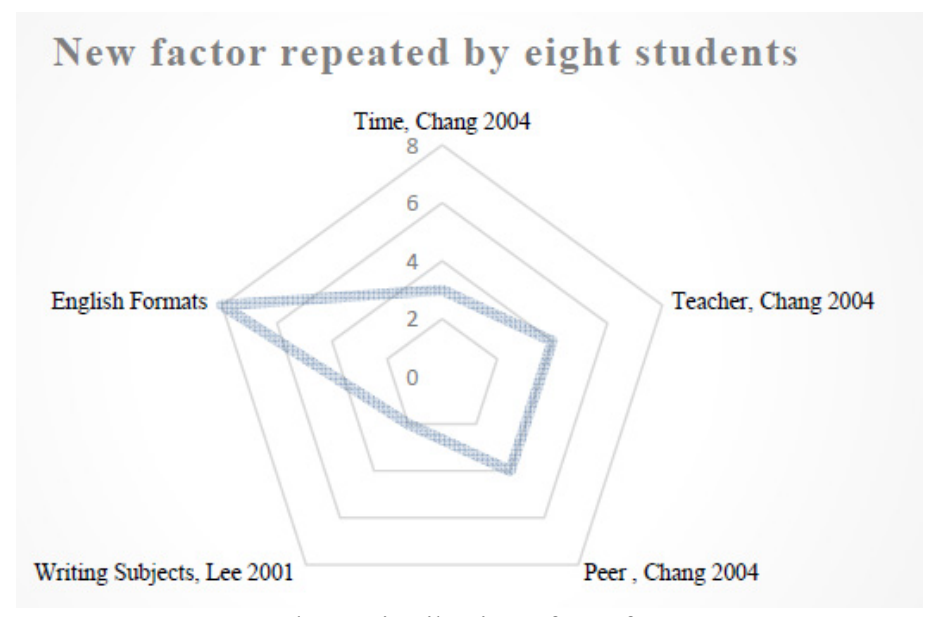

Graph 6. Distributions for 5 factors

Table 1. Factors of writing anxieties

\begin{tabular}{|c|c|c|c|}
\hline Factors & Previous Scholars & $\begin{array}{l}\text { Same Perspectives } \\
\text { from Taiwanese }\end{array}$ & New Factors newly found \\
\hline Time & Chang 2004 & 3 from 17 participants & \\
\hline Teacher & Chang 2004 & 4 from 17 participants & \\
\hline Peer Competition & Chang 2004 & 4 from 17 participants & \\
\hline Wring Subject & Lee, 2001 & 2 from 17 participants & \\
\hline English Formats & This study & 8 from 17 participants & $\begin{array}{l}\text { Repeated by } 8 \text { students } \\
\text { and strongly argued by two } \\
\text { students }\end{array}$ \\
\hline $\begin{array}{l}5 \text { factors from Taiwan } \\
\text { views }\end{array}$ & $\begin{array}{l}4 \text { factor mentioned } \\
\text { previously }\end{array}$ & & 1 updated factor found \\
\hline
\end{tabular}

\section{Discussion}

From the data collected and the themes conceptualized using a constant comparison method, this study revealed that students' anxiety might be aggravated by face problems, which could be caused by teacher evaluation and peer competition. Participants pointed out they felt afraid when thinking of teacher's negative comments or receiving a low score. Some students pointed out peer competition sometimes caused apprehension.

\subsection{Time Restrictions (Graph 1)}

There are undeniable negative impacts from the concern of time restrictions. From the researchers' view, requesting a student to write an abstract or an introduction when they have no experience in doing researches is a little rigid. Unless the instructor gives the students a chance to be more familiar with what research is about, they will naturally feel a restriction in their ability to use imagination to complete an abstract or introduction in limited time is stressful.

Knoch and Elder (2010) point out that limited writing time in tests limits the writers' performance. “...the time restrictions imposed in the test environment, when compared to the writing conditions typical at university, may prevent learners from displaying the kinds of writing skills required in academic contexts." (p. 63) To assist students in developing new writing strategies and develop more reasonable concepts of scoring, homework that can be completed with an extended writing time should be a good solution for the anxiety caused by in class time-limited composition activity. If students cannot complete in-class writing assignments within the limited time, it is better not to force them finish writing. Giving them the option of taking the assignment home to complete is a suggested pedagogy.

\subsection{Teacher Evaluations (Graph 2)}

Caring about teachers' perception of the learner's achievement was regarded as the most important source of 
anxiety. Learners felt their improvements were blocked by depressing feedback from the teachers. Hence, they worried about producing very high-proficiency writing and disappointing their teachers, further hindering their writing ability.

For dealing with frustrating comments, this study suggests counselors as well as writing mentors rather than teachers can be available and helpful. Counselors can play a role that course instructors cannot do well. The reason is to dissipate worry about respect or grade issues. Counselors in writing centers usually play a role in answering questions and offering writing strategies instead of scoring students. "Students' problems, of course, can affect their performance in school, and counselors can sometimes assist students in ways that other instructors cannot. Often counselors and teachers on the same team work together to resolve issues that students face" (Babbitt, 2001, p. 53)

The above point raises awareness for university teachers to care about their professional knowledge of emotional factors as well as know how to be a helper instead of a person who frustrates learners' self-belief and enthusiasm in English writing. Widdowson's (2003) words should guide the writing teachers.

"Learning is essentially a matter of conformity, with teachers directing affairs and students deferring to their authority. When students showed signs of deviation, voluntarily or not, they were brought back into line, and made to see the error of their ways." (Widdowson, 2003, p. 143)

\subsection{Peer Competitions (Graph 3)}

Peer competition is also a factor mentioned in previous studies. (Bailey, 1983) Anxiety from competition occurs when learners compare themselves to others or to an idealized self-image, which they can rarely attain. Some other scholars have a positive view of peer correction and argue it should be practiced in writing class.

Hence, peer interaction, cognitive conflict, and anxiety on grammar (Svalberg, 2012) could be successful educational factors that English teachers should apply by group tasks. In addition, Leaver (2003) indicated "Peer instruction, especially at high levels where peers are themselves quite competent, can be very helpful if used for narrow, specific goals. Perhaps one of your peers understands a specific grammar feature, seemingly like a native speaker, but you do not. Peers can sometimes instruct you in these kinds of things better than a non-teacher native speaker can." (p. 124)

In this study, peer evaluation activity was carried out for students to refer to their classmates' levels and qualities and to examine and help their progresses. The subjects felt anxious and embarrassed about their writing being revealed to their classmates. The researchers viewed this as a result of the students having less experience with this pedagogy. Therefore, this study suggests for the newly applied method of peer correction, some basic theoretical foundation of the advantages of peer correction should be explained to learners. Baserman et al's (2005) statement might persuade high-level non-native speaking learners to let go of their defensive psychological state and not worry about being compared. "Learning Communicates serve to forge relations between students who are engaged in similar studies so that they can learn collaboratively, provide mutual support, and increase each other's engagement in the learning process. (p. 113)

\subsection{Writing Subjects (Graph 4)}

How to make a writing subject interesting to course takers is one of the keys to a successful writing class. Lack of motivation to write about a dull subject was problematic to several students in this research. Therefore, making a tedious topic or boring subject interesting before writers begin to write is a significant task. Besides conducting discussion brain-storming activities and exchanging ideas for each topic in mind, how to establish a dynamic approach to thinking of solutions for uninteresting topics must be considered. According to Richard (2007), there are four strategies for composing articles with uninteresting topics.

First, a current-events that "hook" or grab your readers' interest can be used. In other words, tie your article in with something really is happening in the world of your readers. Second, use a problem plus solution layout when presenting a list of problems. In other words, the author should figure out how to solve the problems existing within a tough topic and try to mentally keep track of the problems and solutions presented by the words. Third, use an anecdote that applies to the story. Quote an older person who fits the world you intend to describe. Fourth, it is acceptable to appeal to the reader's selfishness, and to address your audience with the pronoun "you," in order to emphasize that the author is responsible for interpreting the topic for the author, as well as raising the readers' awareness they should read the article even though the subject might be not exciting. In addition, numerous studies point out that writing can proceed more effortlessly when a topic is familiar to the writer. In contrast, for an unfamiliar topic, the composition can be arduous. (Bereiter \& Scardamalia, 1987). This study recommends that regardless of whether the topics are interesting for the learners, writing lecturers should 
held to review all topic types for the learners who are preparing for their various writing purposes.

\subsection{English Writing Formats (Graph 5)}

The Western English composition format causes anxiety to some course takers and the reasons might be explained by Cook (2008)'s statement: "School children have no particular contact with the foreign culture and no particular interest in it,...their attitudes to L2 users may depend more on the stereotypes from their cultural situations..." (pp. 138-139) For students who had fewer connections with western cultures through international situations, difference in writing forms from Chinese naturally become significant. Kaikkonen (1997) and Kohonen (1999) have clarified this point. They believe people from different cultures have greater differences between them; and this gives rise to dissimilar interpretations and expectations of communication behaviors, resulting in breakdowns and failures in communicative transactions. This study suggests that gently persuading learners to recognize and experience other types of thinking methods as a global citizen might reduce unnecessary anxiety. For example, a lecturer can persuade students that English writing is a way to unite individuals from an assortment of cultural backgrounds. So, our tolerance of human diversity is valued and established. Cross-cultural communication through the western style of English writing aims to bridge the differing cultural ideals and attitudes, so global citizens can establish mutual understanding.

Wilce (2009) mentions learners should have different feelings toward different languages, implying that foreign language learners have to realize and accept one thing: getting accustomed to a new format of communication takes some time. After better understanding a globalized culture integrating a target one with their own, learners will feel less anxiety toward their new learned patterns. "Beyond the diverse grammatical framings of emotion, discursive practice surrounding emotions differ in various speech communities." (Wilce, 2009, p. 80) Later, the learners will be able to reflect on diverse ideologies, and help form opinions based on their input of updated formats of thinking.

\section{Conclusions}

Formats of English writings was concluded to be the major anxiety-causing factors. In addition, the concepts of making topics familiar and interesting, western styles of format learned by writers and arranging a suitable time limit for writing are worth mentioning. In sum, this research found groundbreaking evidence that diverse formats of English writing different from united Chinese style can cause anxiety to Taiwanese learners. Also, it argues that embarrassment and uneasiness caused by teachers and peers needs to be overcome to improve students' writing performances by way of more appropriate teacher training and curriculum design. It is recommended that academic writing lecturers refer to the FLCAS instrument indicating variables of anxiety factors, which can help their students avoid potential and invisible writing anxiety. Current scholars might not know much about anxiety; however, lower levels of anxiety should inspire higher self-confidence and learning motivation, according to most scholars' reports. Therefore, being a qualified and conscientious teachers in our globalized world, teachers should always consider the emotional and cognizant interactive functions inherent in the language learning process.

\section{References}

Arnold, J. (1999). Affect in language learning. N.Y.: Cambridge language teaching library.

Babbitt, M. (2001). Making writing count in an ESL learning community. In I. Leki, (Ed.), Academic writing programs, (pp. 49-60). Alexandria, VA: TESOL.

Baserman, C., Little, J., Bethel, L., Chavkin, T., Fouquette, D., \& Garufis, J. (2005). Reference guide to writing across the curriculum. Indiana, Parlor Press LLC, The WAC Clearinghouse.

Bereiter, C., \& Scardamalia, M. (1987). The psychology of written composition. Hillsdale, N. J.: Lawrence Erlbaum Associates.

Bohn-Gettler, C. M., \& Rapp, D. N. (2014). Emotions in reading and writing. In R. Pekrun, \& L. Linnenbrink-Garcia (Eds.), International handbook of emotions in education. (pp. 437-457). New York, USA: Routledge Journals, Taylor \& Francis Group.

Colleen (2017). When writing is hard, Retrieved from http://www.writingandwellness.com/category/motivation

Cook, V. (2008). Second language learning and language teaching (4th ed.), London: Hodder Education

Coutu, D. (2002). The anxiety of learning. Harvard Business Review, 67(3), 2-8. https://doi.org/10.1109/EMR.2002.1167289

Daud, N. S. M.; Daud, N. M., \& Abu Kassim, N. L. (2005). Second Language writing Anxiety: Cause or Effect. 
Malaysian Journal of ELT Research (MELTA).

Dai, D. Y., \& Sternberg, R. J. (2004). Beyond cognitivism: Toward an integrated understanding of intellectual functioning and development. In D. Y. Dai, \& R. J. Sternberg (Eds.), Motivation, emotion, and cognition: Integrative perspectives on intellectual functioning and development. (pp. 3-38). Mahwah, NJ: Lawrence Erlbaum Associates, Inc. Publishers.

Daly, J. A., \& Miller, M. D. (1975). The empirical development of an instrument to measure writing apprehension. Research in the Teaching of English, 9, 242-249.

Dallos, R. (1976, 2006). The effects of anxiety and intelligence on learning from Programmed Instruction. $\begin{array}{lllll}\text { Innovations in Education \& Training International, } & \text { 13(2), }\end{array}$ https://doi.org/10.1080/1355800760130210

Dornyei, Z. (2009). The psychology of second language acquisition. New York: Oxford University Press.

Gardner, R. C. (1985). Social psychology and second language learning: The role of attitudes and motivation. London: Edward Arnold.

Glaser, B. G., \& Strauss, A. L. (1999). Discovery of grounded theory: Strategies for qualitative research. Chicago: Aldine Publication.

Guo, Y. J., \& Wang, S. C. (2014). Writing anxiety groups: A creative approach for graduate students. Journal of Creativity in Mental Health, 9(3), 366-379. https://doi.org/10.1080/15401383.2014.902343

Horwitz, E. K. (1986). Preliminary evidence for the reliability and validity of a foreign language anxiety scale. TESOL Quarterly, 20(4), 559-562. https://doi.org/10.2307/3586302

Horwitz, E. K., Horwitz, M. B., \& Cope, J. (1986). Foreign language classroom anxiety. The Modern Language Journal, 70(2), 125-133. https://doi.org/10.1111/j.1540-4781.1986.tb05256.x

Ho, M. C. (2016). Exploring writing anxiety and self-efficacy among EFL graduate students in Taiwan. Canadian Center of Science and Education, Higher Education Studies, 6(1), 24-39. https://doi.org/10.5539/hes.v6n1p24

Jee, M. J. (2015). Exploring Korean heritage language learners' anxiety: ‘we are not afraid of Korean!' Journal of Multilingual and Multicultural Development, 37 37), https://doi.org/10.1080/01434632.2015.1029933

Kaikkonen, P. (1997). Learning a culture and a foreign language at school-aspects of intercultural learning. Language Learning Journal, 15, 47-51. https://doi.org/10.1080/09571739785200111

Knoch, U., \& Elder, C. (2010). Validity and fairness implications of varying time conditions on a diagnostic test of academic English writing proficiency system. An international journal of educational technology and applied linguistics, 38(1), 63-74.

Kohonen, V. (1999). Authentic assessment in affective foreign language education. In J. Arnold (Ed.). Affect in Language Learning (pp. 279-294). Cambridge: Cambridge University Press.

Krashen, S. D. (2003). Explorations in language acquisition and use: The Taipei lectures. Portsmouth, NH: Heinemann.

Krashen, S. D. (2016). Applying the Comprehension Hypothesis: Some Suggestions. Retrieved from http://www.sdkrashen.com/content/articles/2004_applying_the_comprehension_hypothesis_krashen.pdf

Lee, S. Y. (2001). The relationship of writing apprehension to the revision process and topic preference: A student perspective. In P. H. Chen, \& Y. N. Leung (Eds.), Selected papers from the tenth international symposium on English teaching (pp. 504-516). Taipei, Taiwan: Crane.

Levine, G. S. (2003). Student and instructor beliefs and attitudes about target language use, first language use, and anxiety: Report of a questionnaire survey. Modern Language Journal, 87(3), 343-364. https://doi.org/10.1111/1540-4781.00194

Lewis, M. (2005). Bridging emotion theory and neurobiology through dynamic systems modeling. Behavioral and Brain Science, 28(2), 169-245. https://doi.org/10.1017/S0140525X0500004X

Meijer, J., \& Oostdam, R. (2011). Effects of instruction and stage-fright on intelligence testing. European Journal of Psychology of Education, 26(1), 143-161. https://doi.org/10.1007/s10212-010-0033-6

Niles, et al. (2014). Randomized controlled trial of expressive writing for psychological and physical health: the 
moderating role of emotional expressivity. Anxiety, Stress and Coping, 27(1), 1-17. https://doi.org/10.1080/10615806.2013.802308

Niles, et al. (2016). Writing content predicts benefit from written expressive disclosure: Evidence for repeated exposure and self-affirmation, Cognition and Emotion 30(2), 258-274. https://doi.org/10.1080/02699931.2014.995598

Onwuegbuzie, A., Philip B., \& Christine, E. D. (1999). Factors associated with foreign language anxiety. Applied Socio Linguistics 20, 218-239. https://doi.org/10.1017/S0142716499002039

Oxford, R. L. (1999), Anxiety and the language learner: new insights. In J Arnold (Ed.), Affect in language learning (pp. 58-67). Cambridge: Cambridge University Press.

Rose, M. (1984). Writer's block: The cognitive dimension. Carbondale: Southern Illinois University Press.

Phelps, E. A. (2005). The interaction of emotion and cognition: Insights from studies of the human amygdale. In L. F. Barrett, P. M. Niedenthal, \& P. Winkielman (Eds.), Emotion and consciousness (pp. 51-66). New York: Guilford Press.

Richard, P. (2007). Four writing tips to make a boring topic interesting. Retrieved from http://www.associatedcontent.com/article/333744/four_writing_tips_to_make_a_boring.html

Rollinson, P. (2005). Using peer feedback in the ESL writing class. ELT Journal, 59(1), 23-30. https://doi.org/10.1093/elt/cci003

Sanders-Reio, Alexander, J. P., Reio Jr., T. G., \& Newman, I. (2014). Do students' beliefs about writing relate to their writing self-efficacy, apprehension, and performance? Learning and Instruction, 33, 1-11. https://doi.org/10.1016/j.learninstruc.2014.02.001

Svalberg, A. M. (2012). Peer interaction, cognitive conflict, and anxiety on a Grammar Awareness course for language teachers. Language Awareness, 21(1-2), 137-155. https://doi.org/10.1080/09658416.2011.639886

Tomlinson, B. (1981, 2016). Reducing student writing anxiety. Proceedings of the Annual Conference of the Western College Reading Association, 14(1), 24-32.

Wynne, C., et al. (2014). Writing anxiety groups: A creative approach for graduate students. Journal of Creativity in Mental Health, 9(3), 366-379. https://doi.org/10.1080/15401383.2014.902343

Widdowson, H. G. (2003). Defining issues in English language teaching. New York: Oxford Press.

Wilce, J. M. (2009), Language and emotion. New York: Cambridge University Press. https://doi.org/10.1017/CBO9780511626692

Worde Von, R. (2003). Students' perspectives on foreign language anxiety. Inquiry, 8(1), 21-40.

Yan, X., \& Wang, H. (2012). Second language writing anxiety and translation: Performance in a Hong Kong tertiary translation class. The Interpreter and Translator Trainer, 6(2), 171-194. https://doi.org/10.1080/13556509.2012.10798835

Young, D. (1992). Language anxiety from the foreign language specialist's perspective: Interviews with Krashen, Omaggio Hadley, Terrell, and Rardin. Foreign Language Annuals, 25, 157-172. https://doi.org/10.1111/j.1944-9720.1992.tb00524.x

\section{Copyrights}

Copyright for this article is retained by the author(s), with first publication rights granted to the journal.

This is an open-access article distributed under the terms and conditions of the Creative Commons Attribution license (http://creativecommons.org/licenses/by/4.0/). 